\title{
Incidence of intravenous drug incompatibilities in intensive care units
}

\author{
Ondrej Machotkaa, Jan Manak ${ }^{b}$, Ales Kubenac, Jiri Vlcek ${ }^{\mathrm{a}}$
}

\begin{abstract}
Aims. Drug incompatibilities are relatively common in inpatients and this may result in increased morbidity/mortality as well as add to costs. The aim of this 12 month study was to identify real incidences of drug incompatibilities in intravenous lines in critically ill patients in two intensive care units (ICUs).

Methods. A prospective cross sectional study of 82 patients in $2 \mathrm{ICUs}$, one medical and one surgical in a 1500-bed university hospital. One monitor carried out observations during busy hours with frequent drug administration. Patients included in both ICUs were those receiving at least two different intravenous drugs.

Results. $6.82 \%$ and $2.16 \%$ of drug pairs were found to be incompatible in the two ICUs respectively. Among the most frequent incompatible drugs found were insulin, ranitidine and furosemide.

Conclusions: The study showed that a significant number of drug incompatibilities occur in both medical and surgical ICUs. It follows that the incidence of incompatibilities could be diminished by adhering to a few simple rules for medication administration, following by recommendations for multiple lumen catheter use. Future prospective studies should demonstrate the effect of applying these policies in practice.
\end{abstract}

Key words: medical error, medical, medication safety, drug administration, drug incompatibilities, intensive care units

Received: April 12, 2014; Accepted with revision: October 16, 2014; Available online: November 6, 2014 http://dx.doi.org/10.5507/bp.2014.057

${ }^{a}$ Department of Social and Clinical Pharmacy, Faculty of Pharmacy in Hradec Kralove, Charles University in Prague, Hradec Kralove, Czech Republic

${ }^{b}$ Department of Gerontology and Metabolism, University Hospital Hradec Kralove

'The Institute of Information Theory and Automation, Academy of Sciences of the Czech Republic, Prague

Corresponding author: Ondrej Machotka, e-mail: ondrej.machotka@faf.cuni.cz

\section{INTRODUCTION}

During the treatment of inpatients, medication errors and unintended side effects are two relatively common drug-related problems which may result in increasing morbidity / mortality as well as add to the cost of the therapy ${ }^{1,2}$. Medication errors have been identified as the main factor limiting the effectiveness and safety of pharmacotherapy ${ }^{3}$. The types and frequency of drug related problems, especially medication errors in preparation and administration, have dramatic implications for the overall quality of nursing care ${ }^{4}$.

Currently only a limited number of physicians and pharmacists have concerned themselves with monitoring these problems in the Czech Republic, with even fewer doing so outside the hospital environment. The authors of early studies and analyses were concentrated on prescription and dispensing errors as well as mistakes caused by patient non-compliance. In contrast, our study was conducted in the hospital environment of an ICU.

Especially in the ICU, rapid response to an emergency is often crucial. For this reason, drugs are usually administered parenterally. Other reasons for this are that drugs are often poorly absorbed via the oral route or patients are unable to receive drugs in other ways. Poorly prepared or wrongly administered parenteral therapy can cause inter alia thrombus formation, severe hypersensitivity reactions and infections ${ }^{5}$. Several studies have specifically focused on intravenous medication administration errors and investigated the incidence ${ }^{6-10}$.

Physicochemical incompatibility is a typical medication error in the administration of parenteral drugs. Incompatibility is defined as the reaction of intravenous drugs resulting in solutions that are no longer optimal for the patient after they are mixed - the stability or structure of the drugs is altered by physical or chemical reactions. Changes in stability can cause changes in drug effectiveness; the increased size of microparticles has been frequently linked to consequences such as therapeutic failure, catheter occlusion, or, in the worst cases, embolism ${ }^{11}$.

A number of studies confirm that this is a significant and increasing problem. Taxis and Barber ${ }^{7}$ have shown that about half of all ward-based intravenous drug preparations and administrations are incorrect. These incompatibilities produce about $20 \%$ of all medication errors and almost $89 \%$ of the overall errors in the administration of drugs $^{8,12}$.

The aim of this study was to survey the incidence and extent of the incompatibilities in a hospital in the Czech Republic and in Eastern Europe with the ultimate goal of making recommendations for reducing the risk of incompatibilities. 


\section{METHODS}

The study was carried out as a comparison of two ICUs at the 1500-bed University Hospital Hradec Kralove. The first was a 20-bed medical ICU specializing in gerontology and metabolism, the second a 12-bed surgical ICU treating adult patients after major surgeries and accidents.

The prospective study led to the identification of real situations of drug incompatibilities. Data collection was conducted gradually from January 2011 to December 2011. 50 patients in the medical ICU and 32 patients in the surgical ICU were assessed prospectively. Only patients who were administered at least two different intravenous drugs were included. The data were collected by the direct observation of nurses administering intravenous medication. For this study we focused on drug incompatibilities excluding both TPN and drugs not found in the database ${ }^{13}$. The observation was performed by one monitor (an independent graduate student in the clinical pharmacy doctoral program) during busy hours with frequent drug administration (6-10 a.m.). The observation was undisguised: nurses and doctors who had previously been informed about the goals of the study, the first of its kind in the Czech Republic. Nurses were clearly informed they would not be identified in to ensure anonymity.

As the source of incompatibilities, Trissel's Handbook on Injectable Drugs ${ }^{13}$ was used. This database contains incompatibility information on 359 different intravenous active ingredients and is often mentioned as the gold standard in IV drug incompatibilities ${ }^{14}$. We focused only on Y-site incompatibilities, indicating two separate drug infusions which are incompatible when infused through the same IV line ${ }^{15}$. There were no standard operating procedures regarding the incompatibilities in the University Hospital Hradec Kralove during the data collection.

For analysis of the data in the prospective studies, we used graph coloring theory ${ }^{16}$. The averages of lumens per patient in both ICUs were compared using t-tests.

The study was approved by the hospital Ethics Committee.

\section{RESULTS}

The results are shown in Table 1.

The first prospective study ( $\mathrm{n}=50$; mean \pm S.D. age; $59.3 \pm 15.0$ years; $54 \%$ female) was performed in the medical ICU. The patients were maintained on a total of 318 IV drugs (mean \pm S.D., $6.3 \pm 3.0$ ) featuring 64 different brands of medications on day two of their ICU stay. Out of a total of 318 IV drugs, $88.7 \%(n=282)$ were found in the database of drug incompatibilities. Out of 220 drug pairs given to the patients through one intravenous line which were found in the database, $6.82 \%(\mathrm{n}=15)$ of the pairs were incompatible, the most frequent compounds being insulin, ranitidine, furosemide and ciprofloxacin (see Table 2).

The second prospective study ( $\mathrm{n}=32$; mean \pm S.D. age; $58.3 \pm 17.2$ years; $28 \%$ female) was performed in the surgical ICU. The patients were maintained on a total of 207 IV drugs (mean \pm S.D., $6.5 \pm 2.4$ ) featuring 48 different brands of medications on day two of their ICU stay. Out

Table 1. Results of our study.

\begin{tabular}{lcc}
\hline & Medical ICU & Surgical ICU \\
\hline No. patients & 50 & 32 \\
No. total administered IV drugs & 318 & 207 \\
Mean of administered drug/patient & 6.3 & 6.5 \\
No. administered drugs found in the database (\%) & $282(88.7)$ & $177(85.5)$ \\
No. brands of medications & 64 & 48 \\
No. drug pairs & 220 & 139 \\
Mean (median) of lumens of catheters per patient & $1.88(1.50)$ & $2.41(3.00)$ \\
Incompatible pairs (\%) & $15(6.82)$ & $3(2.16)$ \\
\hline
\end{tabular}

Table 2. Incompatible drug pairs coinfused through a common IV line.

\begin{tabular}{llcc}
\hline \multicolumn{2}{c}{ Drug combinations (brand names) } & \multicolumn{2}{c}{ No. incompatibilities } \\
\hline Drug A & Drug B & Medical ICU & Surgical ICU \\
\hline Insulin (Humulin) & Ranitidine (Ranital) & 0 \\
Vancomycin (Edicin) & Omeprazole (Helicid) & 2 & 0 \\
Furosemide (Furosemid Biotika) & Ciprofloxacin (Ciprofloxacin Kabi) & 2 & 1 \\
Furosemide (Furosemid Biotika) & Fluconazole (Mycomax) & 2 & 0 \\
Insulin (Humulin) & Noradrenalin (Noradrenalin Leciva) & 2 & 0 \\
Ciprofloxacin (Ciprofloxacin Kabi) & Hydrocortisone (Hydrocortison Valeant) & 1 & 0 \\
Potassium chloride (Kalium chloratum Leciva) & Methylprednisolone (Solu-Medrol) & 1 & 0 \\
Magnesium sulfate (Magnesium sulfuricum Biotika) & Amiodarone (Cordarone) & 0 & 1 \\
Midazolam (Midazolam B. Braun) & Omeprazole (Helicid) & 0 & 1 \\
\hline
\end{tabular}


of a total of 207 IV drugs, $82.9 \%(n=145)$ of them were found in the database of drug incompatibilities. Out of 139 drug pairs found in the database and given to the patients through one intravenous line, $2.16 \%(n=3)$ of the pairs were incompatible, the most frequent compounds being ciprofloxacin, furosemide, midazolam, omeprazole, amiodarone and magnesium sulfate (see Table 2).

\section{DISCUSSION}

Errors in the administration of intravenous drugs have been analyzed in a number of studies ${ }^{7-10,17,18}$, with intravenous drug incompatibilities comprising one subgroup of these problems. Especially in intensive care, during which parenteral drug administration is often complicated by the fact that the number of the concurrently administered drugs exceeds the number of available infusion lines, intravenous drug incompatibilities represent a significant problem.

Our study was designed to identify the real state of intravenous drug incompatibilities at one University hospital in the Czech Republic. The incompatibilities discovered could suggest a lack of interest in the described problem, knowledge deficiencies and/or the absence of a clear strategy or effective tools for reducing the frequency of incompatibilities.

Although the frequency of the incompatibilities does not seem particularly high, the substances found most frequently were often vital drugs like insulin, antibiotics, antiarrhythmics and catecholamines. Even a small decrease in the efficiency of these drugs can cause a significant impact on patients in ICUs.

Comparing the two ICUs involved in our study, the differences in the results are quite interesting. The discrepancies may simply be caused by the differing number of catheter lumens used for the administration of IV drugs in the two different ICUs. The average lumens per patient used in the gerontology and metabolism ICU (1.88) was significantly $(P=0.008)$ lower than the average in the surgical ICU (2.41).

The differences in the types of IV drugs administered in the ICUs could be another reason for the dissimilar results. Although the total amount of administered drugs per patient was higher in both studies conducted in the surgical ICU, the number of brands of used medication was always lower in the surgical ICU in comparison with the medical ICU.

Other studies7,9,10,15,19 focused on intravenous drug incompatibilities show an error rate of incompatibilities similar to the results observed in our study $(3 \%, 18.6 \%$, $0.53 \%, 5.8 \%, 3.4 \%)$. On the other hand, for reasons such as differences in sources of incompatibilities, study samples, types of incompatibilities, methods of collecting data as well as interpretation methods, our results cannot be compared with those in the literature (see Table 3 ).

Despite differences between studies, the incidence of incompatibilities may still be seen as comparable with other studies made in this field.

Based on a comparison with Bertsche et al. ${ }^{15}$ it is possible to show relatively clear strategies towards improvement; the establishment of standard operational procedures, the institution of compatibility charts and the education of ICU nurses in this area have been demonstrated to show promising results.

On the other hand, the establishment of new SOPs can lead to other types of complications, e.g. the shown link between switching to multi-lumen catheters and a subsequent rise in catheter infections ${ }^{20}$, the increase in the volume of drug solvent influencing fluid balance in critically ill patients, as well as the escalating economic burden and increasing demands on ICU staff. These phe-

Table 3. Comparison of similar studies focused on intravenous incompatibilities.

\begin{tabular}{|c|c|c|c|c|c|c|}
\hline & Our study & Bertsche et al. ${ }^{15}$ & Taxis, Barber ${ }^{7}$ & Gikic, Paolo $^{19}$ & Tissot, Cornette ${ }^{9}$ & Westbrook et al. ${ }^{10}$ \\
\hline $\begin{array}{l}\text { No. patients } \\
\text { involved }\end{array}$ & 82 & 25 & 106 & 19 & 26 & Undocumented \\
\hline $\begin{array}{l}\text { No. total } \\
\text { administered IV } \\
\text { drugs }\end{array}$ & 525 & 160 & 430 & Undocumented & Undocumented & 568 \\
\hline $\begin{array}{l}\text { Mean of } \\
\text { administered drug/ } \\
\text { patient }\end{array}$ & 6.4 & 6.4 & 4.1 & 6.5 & Undocumented & Undocumented \\
\hline No. drug pairs & 359 & 516 & Undocumented & 175 & 102 & Undocumented \\
\hline $\begin{array}{l}\text { Database of } \\
\text { incompatibilities }\end{array}$ & $\begin{array}{l}\text { Trissel's } \\
\text { Handbook }^{13}\end{array}$ & KIK database & $\begin{array}{l}\text { Manufacturer's } \\
\text { instructions }\end{array}$ & $\begin{array}{l}\text { More database } \\
\text { sources }\end{array}$ & $\begin{array}{l}\text { Data } \\
\text { systematically } \\
\text { researched }\end{array}$ & $\begin{array}{l}\text { Data systematically } \\
\text { researched }\end{array}$ \\
\hline $\begin{array}{l}\text { Incompatible pairs } \\
(\%)\end{array}$ & $18(5.01)$ & $30(5.8)$ & $12(3.0)$ & $6(3.4)$ & $19(18.6)$ & $3(0.53)$ \\
\hline $\begin{array}{l}\text { Method of data } \\
\text { collecting }\end{array}$ & $\begin{array}{l}\text { Undisguised } \\
\text { bedside } \\
\text { observation }\end{array}$ & $\begin{array}{l}\text { Undisguised } \\
\text { bedside } \\
\text { observation }\end{array}$ & $\begin{array}{l}\text { Disguised } \\
\text { bedside } \\
\text { observation }\end{array}$ & $\begin{array}{l}\text { Undisguised } \\
\text { bedside } \\
\text { observation }\end{array}$ & $\begin{array}{l}\text { Undisguised } \\
\text { bedside } \\
\text { observation }\end{array}$ & $\begin{array}{l}\text { Undisguised bedside } \\
\text { observation }\end{array}$ \\
\hline
\end{tabular}


Table 4. Possible distribution of IV drugs in different lumens of a catheter.

\begin{tabular}{llll}
\hline \multicolumn{2}{c}{ Medical ICU } & \multicolumn{2}{c}{ Surgical ICU } \\
\hline Lumen 1 & Lumen 2 & Lumen 1 & Lumen 2 \\
\hline Ciprofloxacin & Phenytoin & Ciprofloxacin & Phenytoin \\
Clindamycin & Furosemide & Amiodarone & Furosemide \\
Metoclopramide & Omeprazole & Metoclopramide & Insulin \\
Vancomycin & Hydrocortisone & Dobutamine & Midazolam \\
Insulin & Potassium phosphate & Omeprazole & Teicoplanin \\
Potassium chloride & Magnesium sulfate & Potassium chloride & Piperacillin/tazobactam \\
Clarithromycin & Noradrenalin & Noradrenaline & \\
Midazolam & Ranitidine & Propofol & \\
Fluconazole & Ceftriaxone & Ranitidine & \\
& Methylprednisolone & Sufentanil & \\
& & Fluconazole & \\
\hline
\end{tabular}

nomena will be monitored in our next study, which will be focused on the assessment of the new SOPs in practice.

In our study we have partially addressed the problem of switching to multi-lumen catheters. Taking into consideration all of the medications administered in the prospective studies in both ICUs in terms of graph coloring theory ${ }^{11}$, it seems that only the two-lumen catheter remains a viable solution for preventing the problem of incompatibilities, thus switching to multi-lumen catheters should be eliminated as an option. Table 4 shows an example of the potential distribution of IV drugs in our study in terms of excluding the possibility of incompatibilities. The other IV drugs can be added arbitrarily to any one of the groups without presenting problems. The only exceptions are with patients on total parenteral nutrition. For the sake of simplicity for nursing staff, one guideline should be that a single catheter with one lumen designated only for parenteral nutrition is recommended.

Our study has some limitations. First, the prospective observational studies provided real data regarding e.g. specific routes of administration. Nevertheless, some disadvantages of prospective observational studies are the long time needed for data collection, additional demands on the data collectors and ICU staff, as well as difficulty of ensuring that studies are blind. In choosing to use this type of study we kept in mind these advantages and disadvantages. The use of prospective observational studies is in our opinion necessary to identify the real state of incompatibilities.

On the other hand, this could present the problem of the observer interfering with the administering nurse. In our opinion, attempting a totally blind collection of these data is unrealistic. Disguised observation seems to be the optimal method but we chose undisguised observation with the hope of the possibility of only limited interference with the duties of the nurses who cooperated with our study. It is significant that the nurses in our study were in fact unaware of how to solve problems with incompatibilities, most likely due to difficulties in obtaining data about the compatibility and incompatibility of administered IV drugs (lack of information in SPC).
Another limitation of our study is the fact that we did not observe the clinical implications for patients. This would have been very difficult in a routine clinical environment due to the difficult recognition and differentiation of symptoms of incompatibilities. For example a decrease in the activity of one particular drug is difficult to establish in the complexity of the treatments used in the ICU.

The recurrent simplification of medicines to active substances was a drawback as well. Thus it was also necessary to limit the medicines studied to those listed in the selected database. Despite the fact that our database - Trissel's Handbook ${ }^{13}$ is primarily designated for the market in the United States, it is often taken as the gold standard among incompatibility databases ${ }^{14}$. The reasons for exclusion of TPN in the prospective studies were the variability in nutrients composition, the dependence of the incompatibility of individual components on their concentration, and the lack of data on incompatibility of parenteral nutrition solutions.

Working toward the detection and elimination of drug incompatibilities and other drug related problems has been acknowledged as a key goal for the clinical pharmacist $^{21}$. Employing pharmacists with this specialization has still not become sufficiently widespread in Czech hospitals, but it has been on the rise in recent years.

This study has demonstrated that although a significant number of drug incompatibilities occur in both medical and surgical ICUs, in fact only a limited number of medications are involved in these interactions. Besides the amount and type of medications, the most important determinant of the incidence of medication incompatibilities is the usage of single- or multiple lumen intravenous catheters.

\section{CONCLUSION}

Based on our results, the incidence of drug incompatibilities could be theoretically diminished by adhering to a few simple rules for medication administration and following a set of recommendations for multiple lumen catheter 
use. Future prospective studies should demonstrate the effect of applying these policies in practice.

Acknowledgement: The authors would like to thank all participating nurses for the successful collaboration.

This work was supported by grant No 53410-C-2010 of the Charles University Grant Agency and supported in part by grant SVV 267005 administered by Charles University in Prague.

Author contributions: OM: study conception and design, data collection, analysis and interpretation, drafting and manuscript revision; JM: study design, data interpretation, manuscript revision; $\mathrm{AK}$ : data analysis and interpretation; JV: study conception, data interpretation, manuscript revision; all authors: final approval.

Conflict of interest statement: None declared.

\section{REFERENCES}

1. Van den Bemt PM, Egberts TCG, de Jong-van den Berg LT, Brouwers JR. Drug-related problems in hospitalized patients. Drug Safety 2000;22:321-33.

2. Bates DW, Cullen DJ, Laird N, Petersen LA, Small SD, Servi D, Laffel G, Sweitzer BJ, Shea BF, Hallisey R, Vandervliet M, Nemeskal R, Leape LL. Incidence of adverse drug events and potential adverse drug events - implications for prevention. JAMA 1995;274:29-34.

3. Lesar TS, Briceland L, Stein DS. Factors related to errors in medication prescribing. JAMA 1997;277:312-3.

4. Barker KN, Allan EL. Research on drug-use-system errors. Am J Health-Syst Pharm 1995;52:400-3.

5. Bruce J, Wong I. Parenteral Drug Administration Errors by Nursing Staff on an Acute Medical Admissions Ward During Day Duty. Drug Safety 2001;24:855-62.

6. Schneider MP, Cotting J, Pannatier A. Evaluation of nurses' errors associated in the preparation and administration of medication in a pediatric intensive care unit. Pharm World Sci 1998;20:178-82.
7. Taxis K, Barber N. Ethnographic study of incidence and severity of intravenous drug errors. BMJ 2003;326:684-7.

8. Taxis K, Barber N. Incidence and severity of intravenous drug errors in a German hospital. Eur J Clin Pharmacol 2004;59:815-7.

9. Tissot E, Cornette C, Demoly P, Jacquet M, Barale F, Capellier G. Medication errors at the administration stage in an intensive care unit. Intensive Care Med 1999;25:353-9.

10. Westbrook Jl, Rob MI, Woods A, Parry D. Errors in the administration of intravenous medications in hospital and the role of correct procedures and nurse experience. BMJ Qual Saf 2011;20:1027-34.

11. Nemec K, Kopelent-Frank H, Greif R. Standardization of infusion solutions to reduce the risk of incompatibility. Am J Health-Syst Pharm 2008;65:1648-54.

12. Taxis K, Barber N. Causes of intravenous medication errors: an ethnographic study. Qual Saf Health Care 2003;12:343-8.

13. Trissel LA. Handbook on Injectable Drugs, 15th edition: American Society of Health-System Pharmacists 2008.

14. De Giorgi I, Guignard B, Fonzo-Christe C, Bonnabry P. Evaluation of tools to prevent drug incompatibilities in paediatric and neonatal intensive care units. Pharm World Sci 2010;32:520-9.

15. Bertsche T, Mayer Y, Stahl R, Hoppe-Tichy T, Encke J, Haefeli WE. Prevention of intravenous drug incompatibilities in an intensive care unit. Am J Health-Syst Pharm 2008;65:1834-40.

16. Harris JM, Hirst JL, Mossinghoff MJ. Combinatorics and Graph Theory: Springer 2008.

17. Tissot E, Cornette C, Limat S, Mourand JL, Becker M, Etievent JP, Dupond $J$, Jacquet $M$, Woronoff-Lemsi MC. Observational study of potential risk factors of medication administration errors. Pharm World Sci 2003;25:264-8.

18. Han PY, Coombes ID, Green B. Factors predictive of intravenous fluid administration errors in Australian surgical care wards. Qual Saf Health Care 2005;14:179-84.

19. Gikic M, Di Paolo ER, Pannatier A, Cotting J. Evaluation of physicochemical incompatibilities during parenteral drug administration in a paediatric intensive care unit. Pharm World Sci 2000;22(3):88-91.

20. Reed CR, Sessler CN, Glauser FL, Phelan BA. Central venous catheter infections: concepts and controversies. Intensive Care Medicine 1995;21(2):177-83.

21. Wiffen P, Mitchell M, Snelling M, Stoner N. Oxford handbook of clinical pharmacy. Oxford, UK: Oxford University Press 2012. 